\title{
Genotypic Variation in Abscisic Acid Accumulation, Water Relations, and Gas Exchange for Kentucky Bluegrass Exposed to Drought Stress
}

\author{
Zhaolong Wang1 and Bingru Huang ${ }^{2}$ \\ Department of Plant Biology and Pathology, Rutgers University, New Brunswick, NJ 08901.
}

\begin{abstract}
AdDitional index words. Poa pratensis, photosynthesis, stomatal conductance, water potential, electrolyte leakage
Abstract. Drought is a major limiting factor for turfgrass growth. Understanding genetic variations in physiological responses of turfgrass to drought stress would facilitate breeding and management programs to improve drought resistance. This study was designed to evaluate responses of abscisic acid (ABA) accumulation, water relations, and gas exchange to drought stress in four Kentucky bluegrass (Poa pratensis L.) cultivars differing in drought resistance. Plants of 'Midnight' and 'A82-204' (drought resistant) and 'Brilliant' and 'RSP' (drought susceptible) were grown under wellwatered (control) or drought stress conditions for 25 days in growth chambers. Turf quality, leaf water potential $\left(\psi_{\text {leaf }}\right)$, relative water content $(R W C)$, leaf net photosynthesis rate $\left(P_{n}\right)$, and stomatal conductance $\left(g_{s}\right)$ declined, while electrolyte leakage (EL) increased during drought progression in all cultivars. The magnitudes of the change in these parameters were greater for 'RSP' and 'Brilliant' than for 'Midnight' and 'A82-204'. Leaf ABA content in 'RSP' and 'Brilliant' increased sharply after 2 days of stress to as much as 34 times the control level at 10 days of drought. Leaf ABA content in 'Midnight' and 'A82-204' also increased with drought, but to a lesser extent than in the other two cultivars. Leaf ABA level was negatively correlated with $\psi_{\text {leaf }}$ and $\mathrm{g}_{\mathrm{s} \text {. ' }} \mathrm{A82-204}$ ' had a significantly lower ABA accumulation rate with changes in $\psi_{\text {leaf }}$ during drought compared to 'Midnight', 'RSP' and 'Brilliant'; however, no differences in ABA accumulation rate were detected among the latter three cultivars. In addition, leaf $\mathrm{g}_{\mathrm{s}}$ was more sensitive to changes in $\mathrm{ABA}$ accumulation in 'Midnight' and 'A82-204' than in 'RSP' and 'Brilliant'. These results demonstrated that drought tolerant cultivars of Kentucky bluegrass were characterized by lower ABA accumulation and less severe decline in $\psi_{\text {leaf }}$, Pn, $\mathbf{g}_{\mathrm{s}}$, and turf quality during drought stress than drought sensitive cultivars. Drought tolerance of Kentucky bluegrass could be related to sensitivity of stomata to endogenous accumulation of ABA under drought stress conditions.
\end{abstract}

Drought stress can severely limit growth of turfgrasses (Aronson et al., 1987; Beard, 1973, 1989), particularly in urban areas where water availability for landscape irrigation is increasingly limited. Drought injury of turfgrasses involves many physiological and biochemical changes (Carrow, 1996; Howard and Watschke, 1991; Huang et al., 1998; Huang and Gao, 1999; Jiang and Huang, 2000, 2001; Perdomo et al., 1996). Stomatal closure is among the earliest plant responses to drought stress, which can subsequently lead to a reduction in photosynthetic rate and water loss (Blum and Sinmena, 1995; Raschke and Hedrich, 1985).

Abscisic acid (ABA) is an essential constituent of higher plants. This hormone induces rapid stomatal closure and reduction in plant transpiration, thus lessening the decrease in leaf water potential and protecting leaf tissue from turgor loss during drought stress (Borel et al., 1997; Cock et al., 1985; El-Sharkawy and Cock, 1984; Palta, 1984; Trejo et al., 1995; Wang et al., 2002). ABA also induces the expression of several drought-resistant genes by reprogramming the cell to withstand dehydration stress (Bray et al., 1999; Campbell et al., 2001; Furumoto et al., 2000; Jin et al., 2000; Lorenzo et al., 2001; Neill and Burnett, 1999; Tamminen et al., 2001). Genotypic difference in drought tolerance is correlated with changes in ABA concentration and sensitivity in several annual crops (Blum and Sinmena, 1995; Cellier et al., 1998). Drought-susceptible varieties have been found to produce higher levels of ABA than drought-resistant varieties in maize (Zea mays L.) (Ilahi and Dorffling, 1982), spring wheat (Triticum aestivum L. Em. Thell.) (Quarrie and Jones, 1979; Quarrie, 1980; 1981), and sorghum (Sorghum bicolor L. Moench.) (Durley et al., 1983). In contrast, accumulation of leaf ABA has been claimed

Received for publication 7 June 2002. Accepted for publication 18 Dec. 2002. ${ }^{1}$ Postdoctoral research associate.

${ }^{2}$ Associate professor and corresponding author; e-mail huang@aesop.rutgers.edu. to be positively associated with drought resistance in soybean (Glycine max L. Merr.) (Samet et al., 1980) and millet (Pennisetum americanum L.) (Henson et al., 1981). In spite of the contrary results in different species, leaf ABA accumulation has been used as a selection criterion to improve drought tolerance in the breeding program for cereal crops (Innes et al, 1984; Landi et al., 2001; Quarrie, 1989). The research in ABA associated with drought resistance in annual crops has stimulated our search for genetic variation in $\mathrm{ABA}$ accumulation and sensitivity as a means of improving drought resistance in perennial turfgrasses. Such research would help to identify the role of ABA in regulating drought tolerance of turfgrasses and provide guidelines for applications of plant growth regulators in management practices to improve drought resistance.

The objectives of the study were to examine genotypic variation in ABA accumulation and physiological responses to drought stress in four cultivars of Kentucky bluegrass, and to determine the relationship of ABA accumulation and drought resistance.

\section{Materials and Methods}

Plant materials and growth conditions. Two relatively drought-tolerant cultivars (Midnight and A82-204) and two drought-susceptible cultivars (RSP and Brilliant) in Kentucky bluegrass were examined in this study. Sods of equivalent quality ( $15 \mathrm{~cm}$ in diameter and $2 \mathrm{~cm}$ thick) were collected from field plots at Adelphia Turfgrass Experiment Station, Rutgers University, N.J. Sods were washed free of soil before planting in plastic pots (20 $\mathrm{cm}$ in diameter and $40 \mathrm{~cm}$ deep) filled with a mixture of sand and topsoil (fine, montmorillonitic, mesic, aquic arquidolls) $(1: 2, \mathrm{v} / \mathrm{v})$. Plants were grown in a greenhouse for $90 \mathrm{~d}$ and then transferred to growth chambers with a temperature of $22 / 18{ }^{\circ} \mathrm{C}$ (day/night), 14-h photoperiod, and photosynthetically active radiation $(P A R)$ 
of $600 \mathrm{mmol} \cdot \mathrm{m}^{-2} \cdot \mathrm{s}^{-1}$. Grasses were maintained in growth chambers for $15 \mathrm{~d}$ before drought treatment was imposed. Controlled-release fertilizer (17N-6P-10K) was top-dressed twice prior to dry-down to provide a total $\mathrm{N}$ of $17 \mathrm{~g} \cdot \mathrm{m}^{-2}$. Turf was hand-clipped twice weekly to a $6-\mathrm{cm}$ height.

TreatMenTS AND MEASUREMENTS. The experiment consisted of two soil moisture treatments: a) drought stress (irrigation withheld and soil allowed to dry for $25 \mathrm{~d}$ and b) well-watered control (plants irrigated every other day until drainage occurred from the bottom of the pots). Volumetric soil water content in the $0-20 \mathrm{~cm}$ soil layer was monitored to determine soil dryness during drought stress by time domain reflectometry (Soil Moisture Equipment Corp., Santa Barbara, Calif.). The field capacity of the sand and topsoil mix was $27 \% \pm 0.5 \%$ (mean of eight replications \pm standard error), which was measured in eight pots when drainage ceased following watering the soil to complete saturation.

Several physiological measurements were made at 4-d intervals during the experiment. All measurements were made on six young, fully expanded leaves from different plants in each pot. Leaf net photosynthetic rate $(\mathrm{Pn})$ and stomatal conductance $\left(g_{s}\right)$ were measured with a portable gas-exchange system (LI-6400; LI-COR Inc., Lincoln, Nebr.) at a PAR of $800 \mathrm{mmol} \cdot \mathrm{m}^{-2} \cdot \mathrm{s}^{-1}$ and a chamber temperature of $22{ }^{\circ} \mathrm{C}$ from 1000 to $1400 \mathrm{HR}$ at each measurement time. Turf quality was rated visually based on color, density, and uniformity on a scale of 1 (worst, most plants died) to 9 (best, healthy and green plants). Grasses rated at 6 or above were considered to have acceptable quality. Leaf relative water content (RWC) was calculated based on leaf fresh weight, dry weight, and turgid weight measured after soaking leaves in water for $8 \mathrm{~h}$. Leaf samples were dried at $80^{\circ} \mathrm{C}$ in an oven for $72 \mathrm{~h}$ and then dry weight was determined. Six young, fully expanded leaves from different plants in each pot were collected for water potential measurement. Water potential $\left(\psi_{\text {leaf }}\right)$ of individual leaves was measured using a thermocouple psychrometer (Tru Psi, Decagon Devices, Inc., Pullman, Wash.). Cell membrane stability was estimated by measuring electrolyte leakage (EL). Samples of $0.1 \mathrm{~g}$ leaves were rinsed and immersed in $20 \mathrm{~mL}$ of deionized water. The conductivity of the solution $\left(\mathrm{C}_{\text {initial }}\right)$ was measured after the leaves were shaken for $24 \mathrm{~h}$. Leaves then were killed by autoclaving at $140{ }^{\circ} \mathrm{C}$ for $20 \mathrm{~min}$. The conductivity of killed tissues $\left(\mathrm{C}_{\max }\right)$ was measured after samples were cooled to the room temperature. Relative EL was calculated as $\left(\mathrm{C}_{\text {initial }} / \mathrm{C}_{\max }\right) \times 100$.

ABSCISIC ACID EXTRACTION AND ANALYSIS. Extraction and analysis of abscisic acid followed the methods described by Alves and Setter (2000). Fully expanded leaves were extracted in $80 \%$ $[\mathrm{v} / \mathrm{v}]$ methanol (with $1 \%$ glacial acetic acid $[\mathrm{v} / \mathrm{v}]$ and $10 \mathrm{mg} \cdot \mathrm{L}^{-1}$ butylated hydroxytoluene, sample:extraction $=1: 10[\mathrm{w} / \mathrm{v}])$. After centrifuged at $10,000 \mathrm{~g}$ for $10 \mathrm{~min}$, the supernatants were vacuum-dried and resuspended in $20 \%$ methanol. Aliquots $(100 \mathrm{~mL})$ were applied onto $\mathrm{C}_{18}$ chromatography columns ( $25 \mathrm{mg}$, Supelco, Bellefonte, Pa.) for purification. Hydrophilic contaminants were washed out with $200 \mathrm{~mL} \mathrm{20 \%} \mathrm{methanol.} \mathrm{The} \mathrm{ABA-containing}$ fraction was eluted with $200 \mathrm{~mL} \mathrm{50 \%} \mathrm{methanol} \mathrm{(with} 1 \%$ glacial acetic acid, v/v), vacuum-dried, and redissolved in Tris-buffered saline (TBS) solution ( $\mathrm{pH} 7.5$ ). Thirty Bq of ${ }^{3} \mathrm{H}-\mathrm{ABA}$ (A 7090, Sigma Co., Mo.) was added to each sample to monitor loss of ABA during the purification. ABA was quantified by using antiABA monoclonal antibody (Agdia Inc., Elkhart, Ind.) by indirect enzyme linked immunosorbant assay (ELISA) as previously described by Alves and Setter (2000).

Experimental Design AND STATISTICAL ANALYSIS. The experiment consisted of two factors (four cultivars and two soil moisture treatments) with four replications arranged in a completely randomized design. Treatment effects were determined by analysis of variance according to the general linear model procedure of the Statistical Analysis System (SAS Institute, Cary, N.C.). Differences among cultivar means were separated by the least significant difference (LSD, $P \leq 0.05$ ) test and the LSD values are illustrated in the figures. The relationships between leaf water potential and ABA content and between stomatal conductance and $\mathrm{ABA}$ content were determined using the linear regression analysis and the significance of the correlation coefficients and the differences in the slopes of the relationships were tested at a probability level of 0.05 .

\section{Results}

LeAF ABA aCCUMUlation. Under well-watered conditions, leaf ABA content remained a low level in all cultivars, and no cultivar differences were observed (Fig. 1A). Leaf ABA content increased with drought duration (Fig. 1B). There was a 13-fold increase in ABA content in 'RSP' and 'Brilliant' after $4 \mathrm{~d}$ of drought and up to a 34-fold increase after $12 \mathrm{~d}$. ABA contents in 'Midnight' and 'A82-204' did not show significant increases until 4 d. 'RSP' and 'Brilliant' had significantly higher ABA contents than 'Midnight' and 'A82-204', beginning at $4 \mathrm{~d}$ of drought, and their ABA content was about three times greater than that of 'Midnight' and 'A82-204' by 10 d of drought.

Water status AND Relation to ABA aCcumulation. Soil water content declined rapidly from $27 \%$ to $11 \%$ within the first

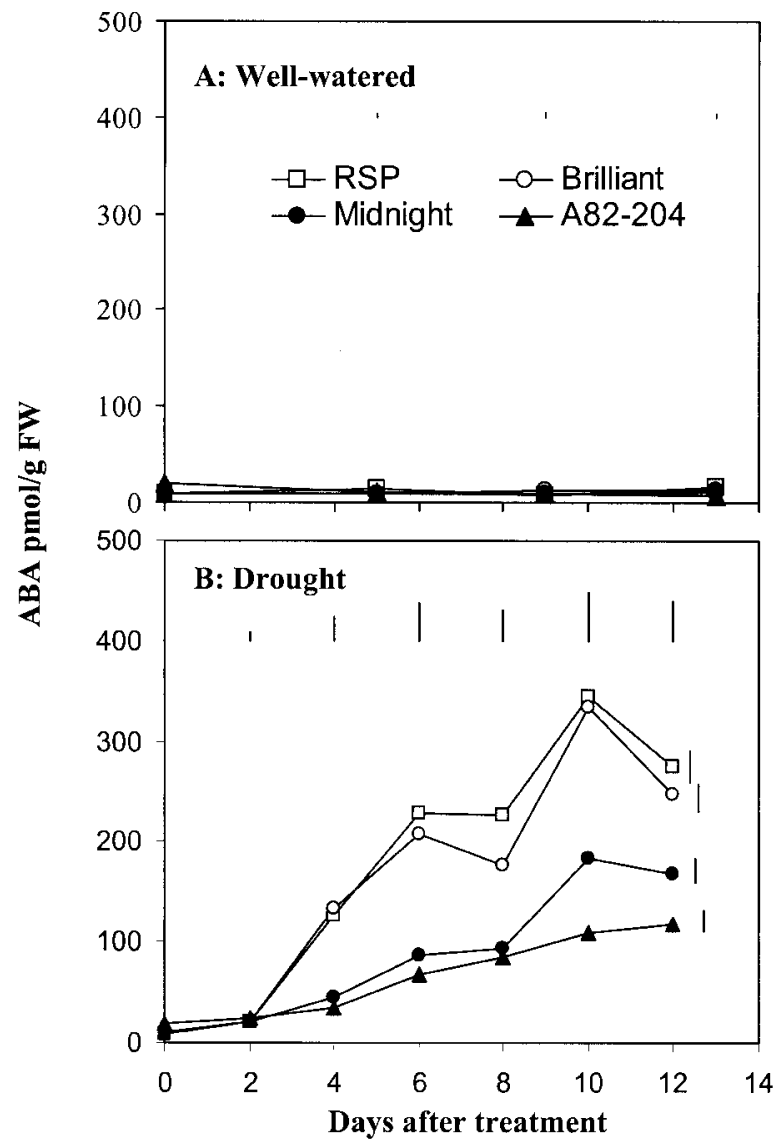

Fig. 1. Leaf ABA accumulation in response to drought stress. Vertical bars on the top are LSD values $(P=0.05)$ for cultivar comparisons at a given day of treatment. Vertical bars on the right are LSD values $(P=0.05)$ for comparisons of changes over treatment duration within the cultivar. 


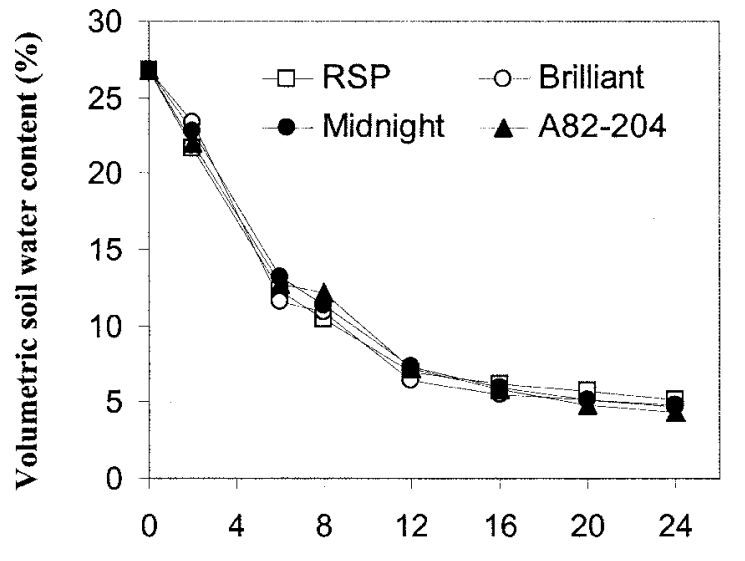

Days after treatment

Fig. 2. Volumetric soil water content $(0$ to $20 \mathrm{~cm})$ changes during the drought stress.

$8 \mathrm{~d}$ of drought stress and to $\approx 5 \%$ after $12 \mathrm{~d}$ and remained at this level until the end of the experiment ( $24 \mathrm{~d}$ ) (Fig. 2). Soil drying rates were similar for all four cultivars.

Leaf water potential $\left(\psi_{\text {leaf }}\right)$ and RWC remained constant during the experimental period, and cultivars were not different in either parameter under well-watered conditions (Fig. 3A and C). $\psi_{\text {leaf }}$ and RWC declined with progressive drought in all cultivars, and the decline was more pronounced for 'RSP' and 'Brilliant' than for 'Midnight' and 'A82-204' (Fig. 3B and D). 'Midnight' and 'A82-204' maintained higher $\psi_{\text {leaf }}$ and RWCs than 'RSP' and 'Brilliant', beginning $4 \mathrm{~d}$ after drought stress. By the end of the experiment, almost all leaves of 'RSP' and 'Brilliant' were desiccated and brown, while some leaves of 'Midnight' and 'A82-204' remained turgid and green.

ABA content in leaves of stressed plants was negatively and linearly correlated with $\psi_{\text {leaf }}$ for all cultivars (Fig. 4). No significant differences were detected in the slopes of the lines for 'Midnight', 'RSP' and 'Brilliant'. The slope of the line for 'A82-204' was significantly less steep than those for the other three cultivars.

Photosynthesis AND STOMATAL CONDUCTANCE IN RELATION To ABA aCCumulation. Leaf Pn remained constant for all cultivars under well-watered conditions, and 'Midnight' had the lowest Pn among the four cultivars (Fig. 5A). Pn declined to below the initial level after $8 \mathrm{~d}$ of drought stress for all cultivars. The decline in Pn for 'RSP' and 'Brilliant' was $80 \%$ while the decline in Pn for 'Midnight' and 'A82-204' was 50\% at 8 d of stress. 'RSP' and 'Brilliant' had significantly lower Pn than 'Midnight' at 8, 12, and $16 \mathrm{~d}$ of stress and 'A82-204' at 8 and $16 \mathrm{~d}$, but not after $12 \mathrm{~d}$ of stress (Fig. 5B).

Under well-watered conditions, 'A82-204' had higher $g_{s}$ than the other three cultivars. No significant difference in $g_{s}$ was observed among 'Midnight', 'RSP', and 'Brilliant' (Fig. 6A). Stomatal conductance declined significantly at $4 \mathrm{~d}$ of drought stress, compared to the initial level and reached the lowest level at $8 \mathrm{~d}$ for 'Midnight' and 'A82-204' and $12 \mathrm{~d}$ for 'RSP' and 'Brilliant'. 'RSP' and 'Brilliant' had higher $\mathrm{g}_{\mathrm{s}}$ than 'Midnight' and 'A82-204' at $8 \mathrm{~d}$, but lower $g_{s}$ at $12 \mathrm{~d}$ of drought (Fig. 6B).

Stomatal conductance was negatively and lin-
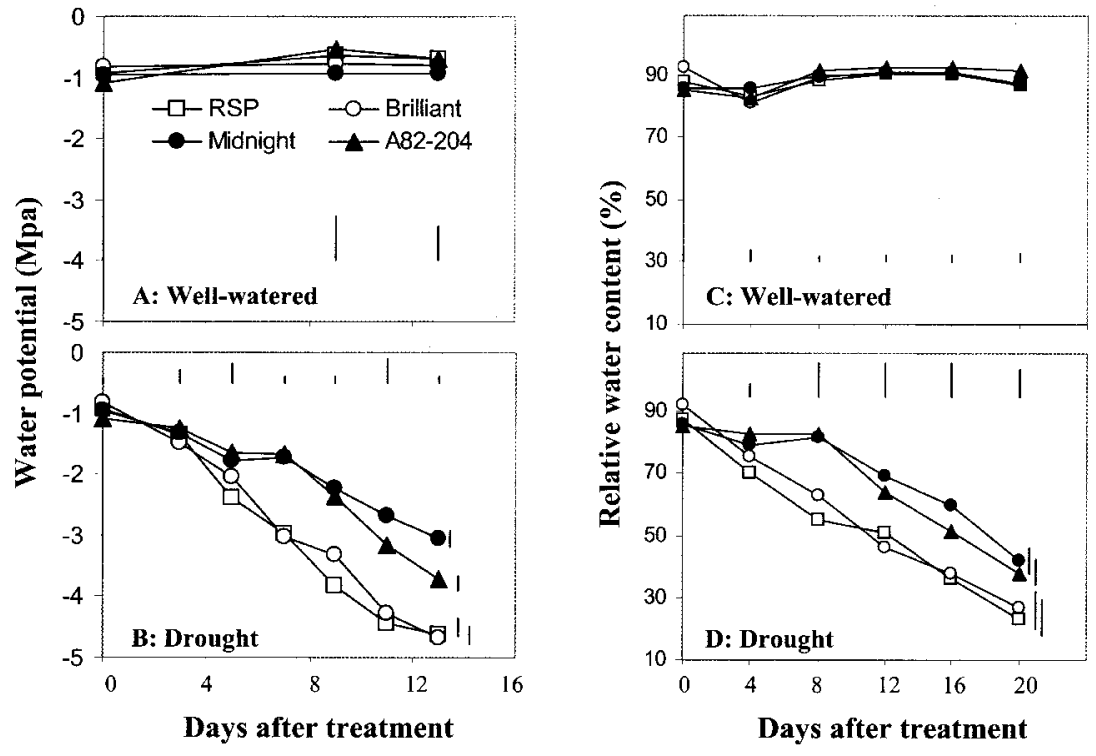

early correlated with ABA content in leaves of stressed plants for all cultivars during the first $12 \mathrm{~d}$ of drought stress (Fig. 7). The slopes of the lines differed for the drought-sensitive and drought-tolerant cultivars. The slopes of the lines for 'Midnight' and 'A82-204' were significantly greater than those for 'RSP' and 'Brilliant'.

Turf Quality AND MEMbrane STABILITY. The initial level of turf quality was approximately 8.0 for all four cultivars under well-watered conditions (Fig. 8A). When plants were subjected to drought stress, turf quality declined for all cultivars, but to a greater extent for 'RSP' and 'Brilliant' than for 'Midnight' and 'A82-204' (Fig. 8B). 'Midnight' remained at the acceptable level (turf quality $=6$ ) during most of the experimental period, while turf quality of 'RSP' and 'Brilliant' declined to below the acceptable level at $12 \mathrm{~d}$ of stress. 'Midnight' and 'A82-204' had significantly higher turf quality than 'RSP' and 'Brilliant', beginning at $8 \mathrm{~d}$ of drought.

Leaf EL increased with drought stress in all cultivars (Fig. 9A). The increase in EL for 'RSP' and 'Brilliant' was more pronounced than that for 'Midnight' and 'A82-204'. Leaf EL for 'Midnight' and 'A82-204' did not increase above the initial level until $16 \mathrm{~d}$ of drought (Fig. 9B). 'RSP' and 'Brilliant' had significantly higher EL than 'Midnight' and 'A82-204', beginning of $4 \mathrm{~d}$ of drought.

\section{Discussion}

Abscisic acid increased significantly with drought in all four cultivars of Kentucky bluegrass studied. Although such increases in ABA have been frequently documented in other species (Alves and Setter, 2000; Cao et al., 2000; Jin et al., 2000; Li et al., 2000; Ober et al., 1991; Sharp et al., 1994; Stoll et al., 2000), few studies have documented changes in ABA levels with drought in turfgrasses. Kentucky bluegrass cultivars differing in physiological responses to drought showed different patterns of ABA accumulation in leaves during drought stress. Leaf ABA content

Fig. 3. Responses of leaf water potential $\left(\psi_{\text {leaf }}\right)$ and relative water content (RWC) to drought stress. Vertical bars on the top or bottom are LSD values $(P=0.05)$ for cultivar comparisons at a given day of treatment. Vertical bars on the right are LSD values $(P=0.05)$ for comparisons of changes over treatment duration within the cultivar. 


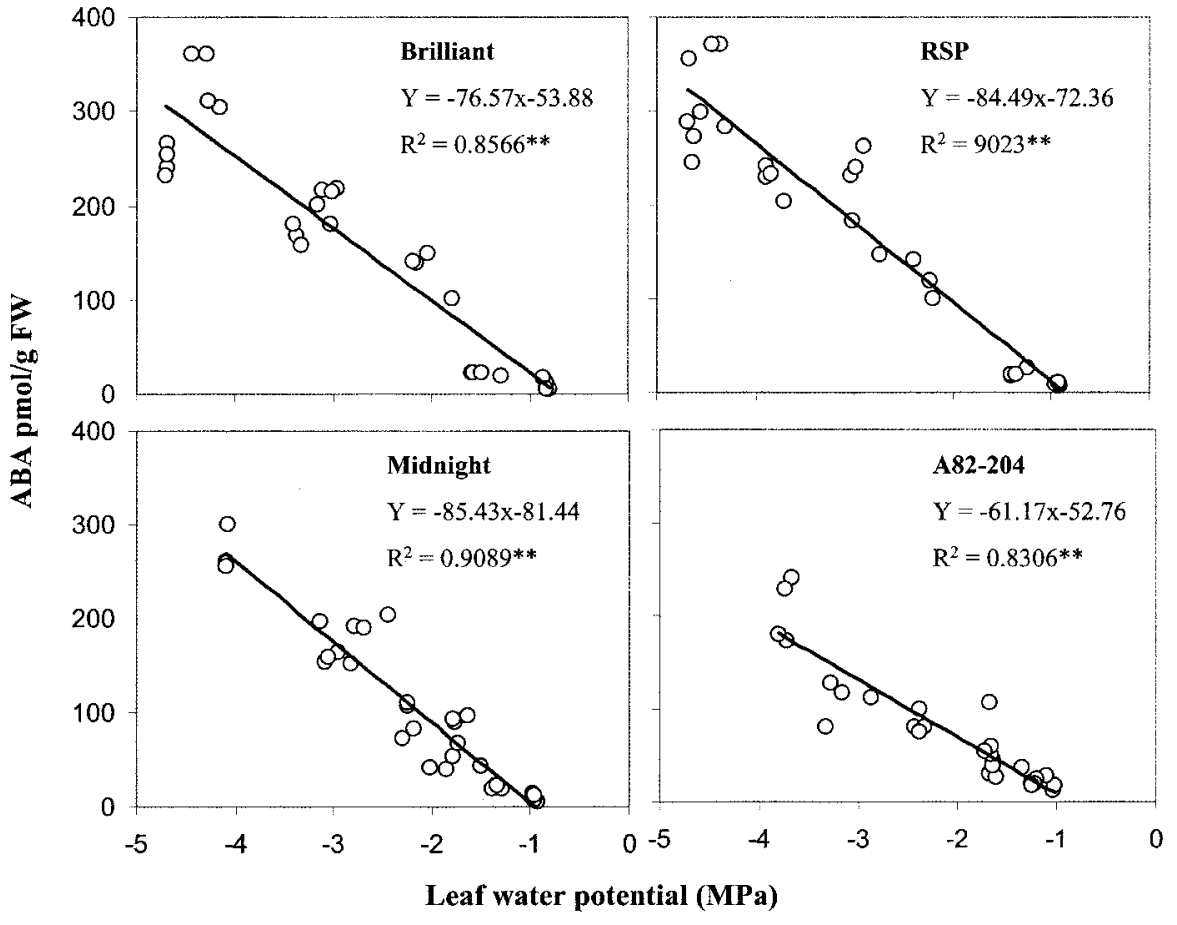

Fig. 4. The relationship between leaf ABA content and leaf $\psi$ in drought-stressed plants of four cultivars. Lines are fitted linear regressions. $\mathrm{df}=26$. Correlation coefficients $(r)$ are indicated. The difference in the slopes of each cultivar was tested by ANOVA $(P=0.05)$.

increased more dramatically in 'RSP' and 'Brilliant' which showed more rapid and severe decline in turf quality, $\psi_{\text {leaf }}, \mathrm{RWC}, \mathrm{Pn}, \mathrm{g}_{\mathrm{s}}$ and cell membrane stability than that in 'Midnight' and 'A82204'. The large variation among genotypes in the rate of drying prevented measurements of ABA content for each genotype at the same level of internal water stress. Stikic and Davies (2000) reported more rapid accumulation of ABA in drought susceptible than resistant lines of maize (Zea mays).

Soil drying rates were similar for all four cultivars (Fig. 2). However, 'Midnight' and 'A82-204' maintained significantly higher RWC and $\psi_{\text {leaf }}$ after $8 \mathrm{~d}$ of drought. At the same day of drought stress or same level of soil moisture, 'Midnight' and 'A82-204' accumulated less ABA in leaves than drought-sensitive 'RSP' and 'Brilliant'. ABA is a stress-induced hormone and its accumulation is largely controlled by leaf water status (Quarrie and Jones, 1979; Quarrie, 1989). The lower ABA accumulation in 'Midnight' and 'A82-204' during drought stress further illustrated that these two cultivars experienced less severe drought stress which could be due to their superior dehydration avoidance, as demonstrated by their relatively higher $\psi_{\text {leaf }}$ and RWC under the same soil moisture conditions.

Stomatal conductance of drought resistant cultivars (Midnight and A82-204) declined to a level lower than that of the two sensitive cultivars (Brilliant and RSP) at $8 \mathrm{~d}$ of drought when soil moisture was $\approx 12 \%$, but was maintained at a higher level during the remaining stress period (12 to $16 \mathrm{~d}$ ) when soil moisture decreased to $6 \%$. Stomatal conductance of 'Brilliant' and 'RSP' rapidly dropped to near zero by $12 \mathrm{~d}$. Complete stomatal closure for 'RSP' and 'Brilliant' at 12 and $16 \mathrm{~d}$ could have resulted from leaf desiccation, which was indicated by their extremely low water content (below 30\%) and water potential (below $-4 \mathrm{MPa}$ ) at this time of drought stress (Fig. 3). The rapid decline in stomatal conductance or stomata closure at the earlier time, or mild drought stress, for 'Midnight' and 'A82-204' may lead to less transpiration, reducing drought damage during the prolonged stress period. This was supported by the data on leaf water status and EL. EL of 'Brilliant' and 'RSP' increased rapidly at 12 and $16 \mathrm{~d}$, while EL of 'Midnight' and 'A82-204' still remained at a relatively lower level (Fig. 8). The maintenance of stomatal conductance for 'Midnight' and 'A82-204' during prolonged, severe drought stress would help plants to maintain photosynthesis, and thus to survive prolonged drought. In fact, net photosynthetic rates of 'Midnight' and 'A82-204' were 4.2 and $0.8 \mathrm{mmol} \mathrm{CO}_{2} / \mathrm{m}^{-1} \cdot \mathrm{s}^{-1}$, respectively, at 16 $\mathrm{d}$ of drought, while Pn became negative for both 'RSP' and 'Brilliant' which $\mathrm{g}_{\mathrm{s}}$ dropped to zero during prolonged drought.

ABA accumulation has been found to protect plants from damage by drought by inducing stomatal closure, thus reducing water loss via transpiration during early or mild drought stress (Harris and Outlaw, 1991; Wilkinson and Davies, 1997).ABAregulation of drought tolerance may involve both the sensitivity of ABA biosynthesis to changes in plant water status and the sensitivity of the stomata to the changes in ABA concentration (Quarrie and Jones, 1979). The rates of change in $g_{s}$ with leaf $A B A$ concentration for 'Midnight' and 'A82-204' were significantly greater than those

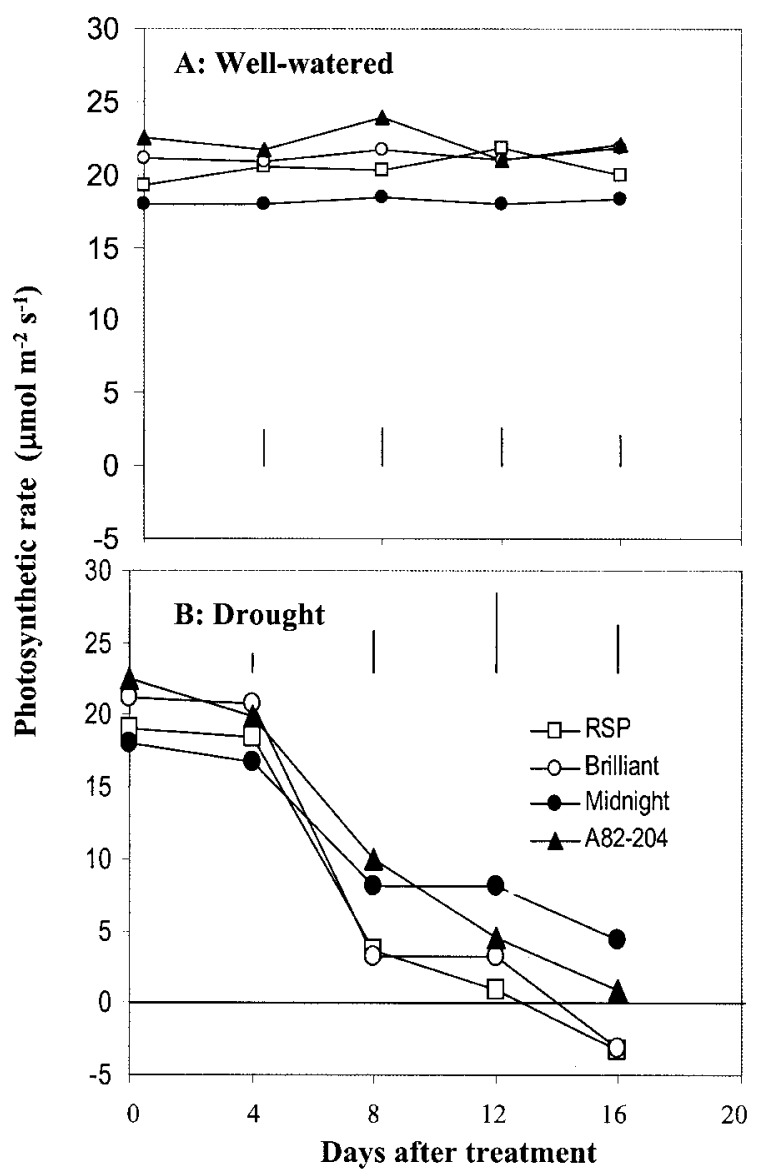

Fig. 5. Responses of single leaf photosynthetic rate (Pn) to drought stress. Vertical bars are LSD values $(P=0.05)$ for treatment and cultivar comparisons at a given day of treatment. 


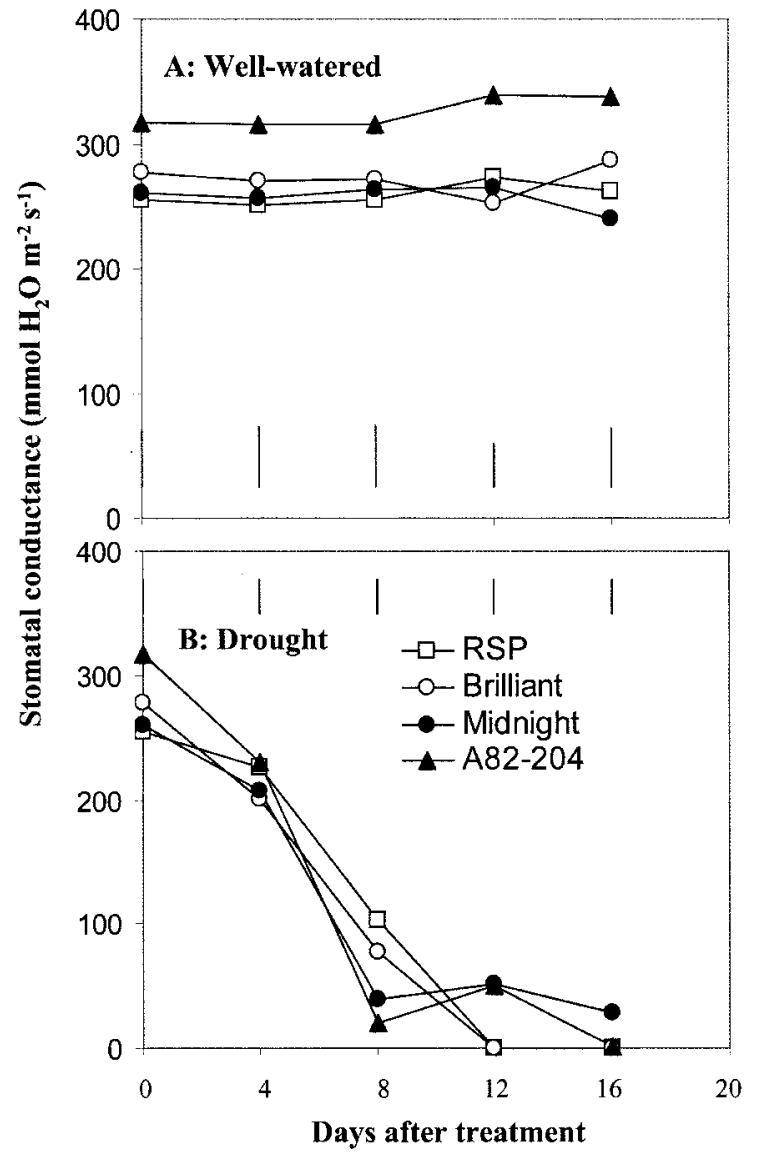

Fig. 6. Responses of stomatal conductance $\left(g_{s}\right)$ to drought stress. Vertical bars on the top or bottom are LSD values $(P=0.05)$ for cultivar comparisons at a given day of treatment. Vertical bars on the right are LSD values $(P=0.05)$ for comparisons of changes over treatment duration within the cultivar.

for 'RSP' and 'Brilliant' (Fig. 7), which indicated that stomata in leaves of drought-resistant cultivars were more sensitive to ABA accumulation than in drought-susceptible cultivars of Kentucky bluegrass. The sensitivity of stomata to ABA changes also varied with genotype in other species (Cellier et al., 1998; Quarrie and Jones, 1979). The high ABA sensitivity of droughtresistant cultivars may lead to early stomatal closure during short-term drought and limit further water loss, thus lessening damage to cell membranes and turf quality decline caused by soil drying. However, effects of prolonged or severe drought on leaf water status and $g_{\mathrm{s}}$ may be ABA-independent and controlled by other factors (Holbrook et al., 2002; Ridolfi et al., 1996). Under extended or severe drought conditions, many other factors, such as osmotic adjustment associated with solute accumulation, contribute to the maintenance of cell turgor, $\mathrm{g}_{\mathrm{s}}$, and water status in plants (Bohnert and Jensen, 1996; Nilsen and Orcutt, 1996; Zhang and Archbold, 1993a, 1993b).

In conclusion, drought tolerant cultivars of Kentucky bluegrass were characterized by lower ABA accumulation and less severe decline in $\psi_{\text {leaf }}$, Pn, $g_{s}$, and turf quality during drought stress. Cultivars differing in drought response varied in stomatal sensitivity to changes in ABA level during drought. Drought tolerance of Kentucky bluegrass could be related to sensitivity of stomata to endogenous accumulation of ABA under short-term or mild drought stress conditions.

\section{Literature Cited}

Alves, A.A.C. and T.L. Setter. 2000. Response of cassava to water deficit: Leaf area growth and abscisic acid. Crop Sci. 40:131-137.

Aronson, L.J., A.J. Gold, and R.J. Hull. 1987. Cool-season turfgrass responses to drought stress. Crop Sci. 27:1261-1266.

Beard, J.B. 1973. Turfgrass: Science and culture. Prentice-Hall, Englewood Cliffs, N.J.

Beard, J.B. 1989. Turfgrass water stress: Drought resistance components, physiological mechanism, and species-cultivar diversity, p. 23-28. In: H. Takatoh (ed.). Proc. $6^{\text {th }}$ Intl. Turf. Sci., Tokyo, Japan, August 1989. Jpn. Soc. Turf Sci., Tokyo.

Blum, A. and B. Sinmena. 1995. Isolation and characterization of variant wheat cultivars for ABA sensitivity. Plant Cell Environ. 18:77-83.

Bohnert, H.J. and R.G. Jensen. 1996. Strategies for engineering waterstress tolerance in plants. Trends Biotechnol. 14:89-97.

Borel, C., T. Simonneau, D. This, and F. Tardieu. 1997. Stomatal conductance and ABA concentration in the xylem sap of barley lines of contrasting genetic origins. Austral. J. Plant Physiol. 24:607-615.

Bray, E.A., T.Y. Shih, M.S. Moses, A. Cohen, R. Imai, and A.L. Plant. 1999. Water-deficit induction of a tomato $\mathrm{H} 1$ histone requires abscisic acid. Plant Growth Regulat. 29:35-46.

Campbell, J.L., N.Y. Klueva, K. Zheng, J. Nieto-Sotelo, T.H.D. Ho, and H.T. Nguyen. 2001. Cloning of new members of heat shock protein HSP101 gene family in wheat (Triticum aestivum (L.) Moench) inducible by heat, dehydration, and ABA. Biochim. Biophys. Acta. 1517:270-277.

Cao, W.X., Z.L. Wang, and T.B. Dai. 2000. Changes in levels of endogenous plant hormones during floret development in wheat genotypes

Fig. 7. The relationship between stomatal conductance $\left(g_{s}\right)$ and leaf ABAcontent in drought-stressed plants of four cultivars within $12 \mathrm{~d}$ of drought stress. Lines are fitted linear regressions. $\mathrm{df}=14$. Correlation coefficients $(r)$ are indicated. The difference in the slopes of each cultivar was tested by ANOVA $(P=0.05)$.
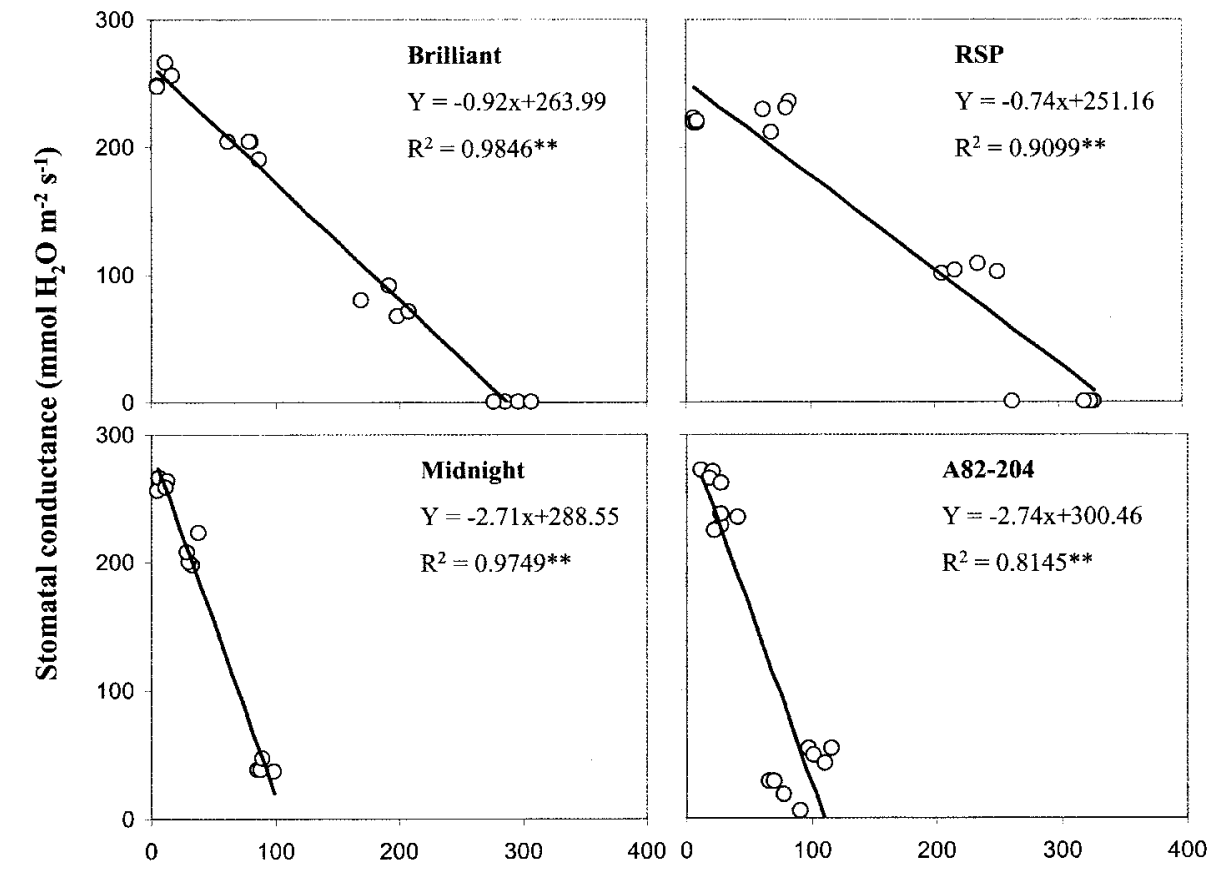

ABA pmol/gFW 


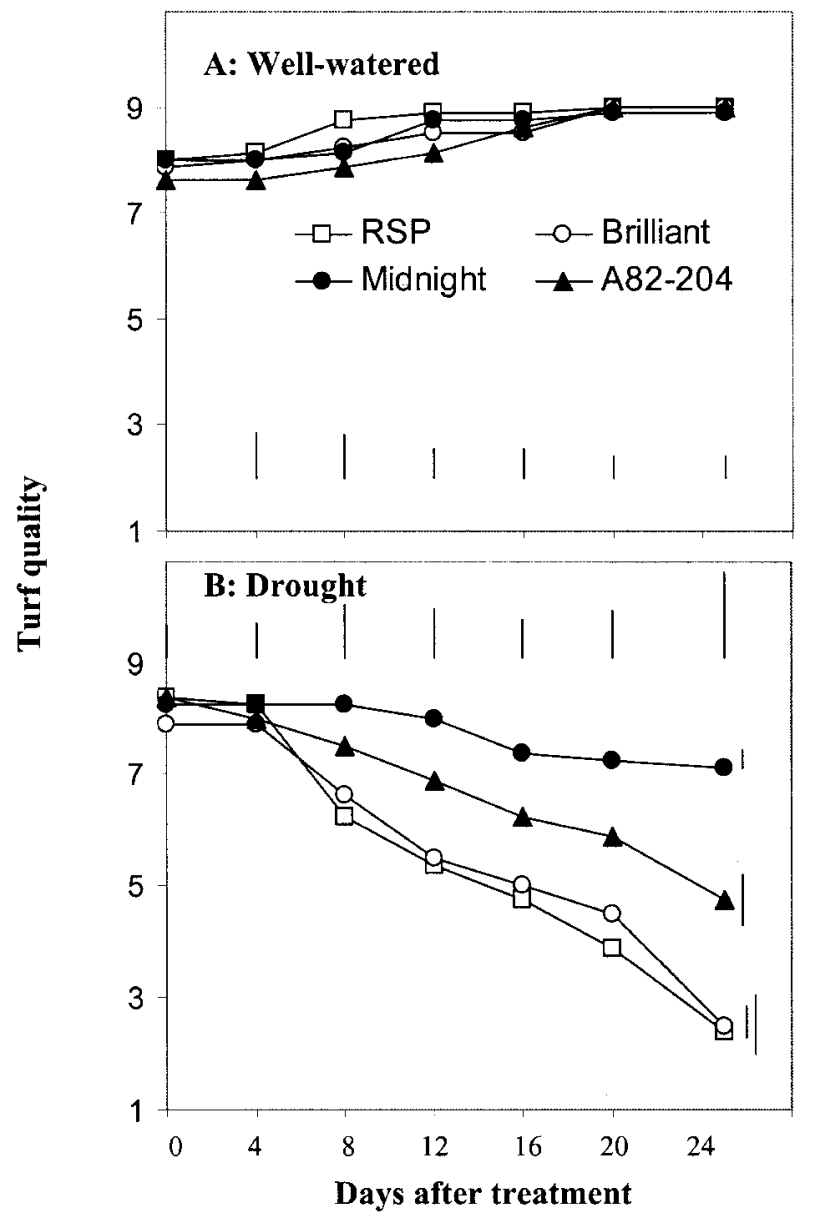

Fig. 8. Responses of turf quality to drought stress. Turf quality was rated visually on a scale of one (worst) to nine (best) based on color, uniformity, and density. Grasses rated at six or above were considered to have acceptable quality. Vertical bars on the top or bottom are LSD values $(P=0.05)$ for cultivar comparisons at a given day of treatment. Vertical bars on the right are LSD values $(P=0.05)$ for comparisons of changes over treatment duration within the cultivar.

of different spike sizes. Acta Bot Sin. 42:696-700.

Carrow, R.N. 1996. Drought avoidance characteristics of diverse tall fescue cultivars. Crop Sci. 36:371-377.

Cellier, F., G. Conejero, J.C. Breitler, and F. Casse. 1998. Molecular and physiological responses to water deficit in drought-tolerant and drought-sensitive lines of sunflower. Plant Physiol. 116:319-328.

Cock, J.H., M.C.M. Proto, and M.A. El-Sharkawy. 1985. Water use efficiency of cassava. III. Influence of air humidity and water stress on gas exchange of field growth cassava. Crop Sci. 25:265-272.

Durley, R.C., T. Kannangara, N. Seetharama, and G.M. Simpson. 1983. Drought resistance of sorghum bicolor. V. Genotypic differences in the concentrations of free and conjugated abscisic, phaseic and indole-3acetic acids in leaves of field-grown drought-stressed plants. Can. J. Plant Sci. 63:131-145.

El-Sharkawy, M.A. and J.H. Cock. 1984. Water use efficiency of cassava. I. Effects of air humidity and water stress on stomatal conductance and gas exchange. Crop Sci. 24:497-502.

Furumoto, T, S. Hata, and K. Izui, 2000. Isolation and characterization of cDNAs for differentially accumulated transcripts between mesophyll cells and bundle sheath strands of maize leaves. Plant Cell Physiol. 41:1200-1209.

Harris, M.J. and W.H. Outlaw, Jr. 1991. Rapid adjustment of guard-cell abscisic acid levels to current leaf-water status. Plant Physiol. 95: 171-173.

Henson, I.E., V. Mahalakshmi, F.R. Bidinger, and G. Alagarswamy. 1981. Genotypic variation in pearl millet (Pennisetum americanum (L.) Leeke), in the ability to accumulate abscisic acid in response to water stress. J. Expt. Bot. 32:899-910.

Holbrook, N.M., V.R. Shashidhar, R.A. James, and R. Munns. 2002.

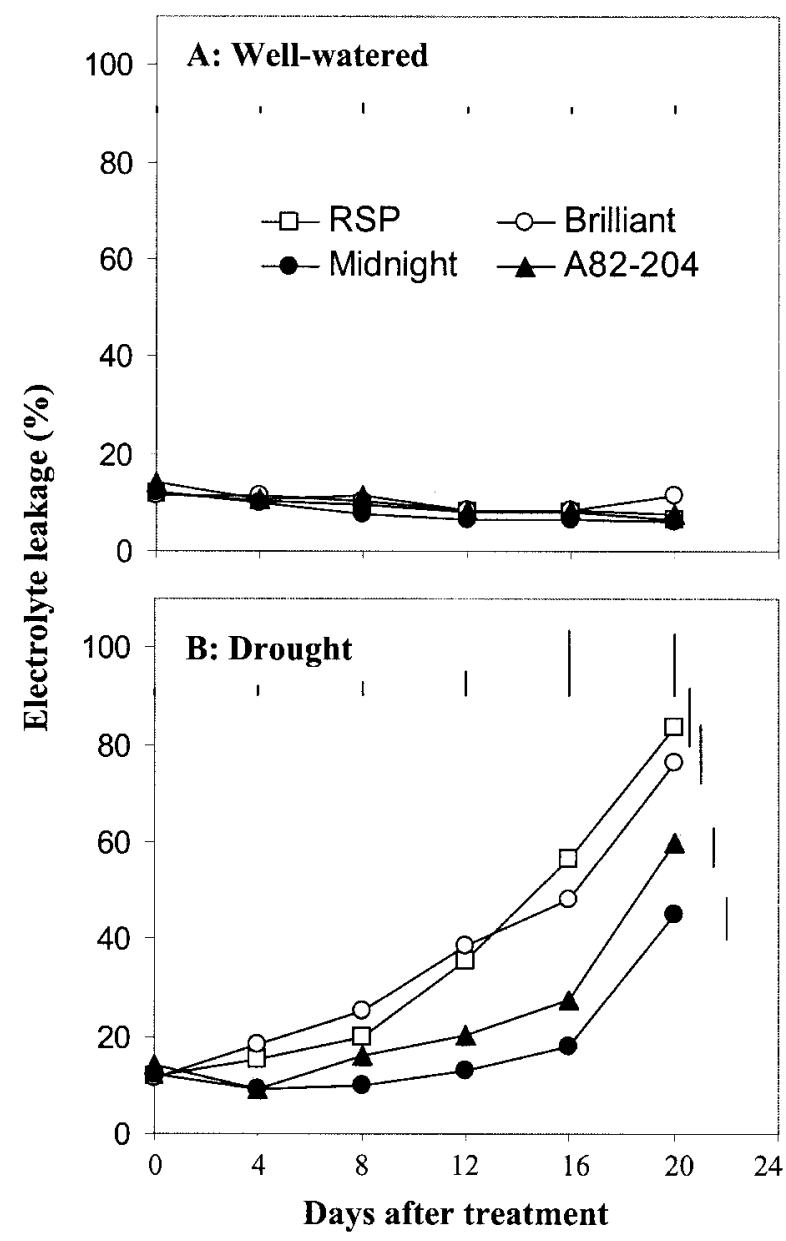

Fig. 9. Responses of Electrolyte leakage (EL) to drought stress. Vertical bars on the top or bottom are LSD values $(P=0.05)$ for cultivar comparisons at a given day of treatment. Vertical bars on the right are LSD values $(P=0.05)$ for comparisons of changes over treatment duration within the cultivar.

Stomatal control in tomato with ABA-deficient roots: Response of grafted plants to soil drying. J. Expt. Bot. 53:1503-1514.

Howard, H. and T.L. Watschke. 1991. Variable high-temperature among Kentucky bluegrass cultivars. Agron. J. 83:689-693.

Huang, B., J.D. Fry, and B. Wang. 1998. Water relations and canopy characteristic of tall fescue cultivars during and after drought stress. HortScience 33:837-840.

Huang, B. and H. Gao. 1999. Physiological responses of diverse tall fescue cultivars to drought stress. HortScience 34:897-901.

Ilahi, I. and K. Dorffling. 1982. Changes in abscisic acid and proline levels in maize varieties of different drought resistance. Physiol. Plant. 55:129-135.

Innes, P., R.D. Blackwell, and S.A Qurrie. 1984. Some effects of genetic variation in drought-induced abscisic acid accumulation on the yield and water use of spring wheat. J. Agr. Sci. 102:341-351.

Jiang, Y. and B. Huang. 2000. Effects of drought or heat stress alone and in combination on Kentucky bluegrass. Crop Sci. 40:1358-1362.

Jiang, Y. and B. Huang. 2001. Drought and heat stress injury to two cool-season turfgrasses in relation to antioxidant metabolism and lipid peroxidation. Crop Sci. 41:436-442.

Jin, S., C.C.S. Chen, and A.L. Plant. 2000. Regulation by ABA of osmotic-stress-induced changes in protein synthesis in tomato roots. Plant Cell Environ. 23:51-60.

Landi, P., M.C. Sanguineti, S. Conti, and R. Tuberosa. 2001. Direct and correlated responses to divergent selection for leaf abscisic acid concentration in two maize populations. Crop Sci. 41:335-344.

Li, J., X.Q. Wang, M.B. Watson, and S.M. Assmann. 2000. Regulation of abscisic acid-induced stomatal closure and anion channels by guard cell AAPK kinase. Science 287:300-303.

Lorenzo, O., D. Rodriguez, G. Nicolas, P.L. Rodriguez, and C. Nicolas. 2001. A new protein phosphatase 2C (FsPP2C1) induced by abscisic 
acid is specifically expressed in dormant beechnut seeds. Plant Physiol. 125:1949-1956.

Neill, S.J., and E.C. Burnett. 1999. Regulation of gene expression during water deficit stress. Plant Growth Regulat. 29:23-33.

Nilsen, E.T. and D.M. Orcutt. 1996. Physiology of plants under stress. Wiley, New York. p. 322-361.

Ober,E.S., T.L.Setter,J.T.Madison, J.F.Thompson, and P.S.Shapiro. 1991. Influence of water deficit on maize endosperm development. Enzyme activities and RNA transcripts of starch and zein synthesis, abscisic acid, and cell division. Plant Physiol. 97:154-164.

Palta, J.A. 1984. Influence of water deficits on gas-exchange and the leaf area development of cassava cultivars. J. Expt. Bot. 35:1441-1449.

Perdomo, P., J.A. Murphy, and G.A. Berkowitz. 1996. Physiological changes associated with performance of Kentucky bluegrass cultivars during summer stress. HortScience 31:1182-1186.

Quarrie, S.A. and H.G. Jones. 1979. Genotypic variation in leaf water potential, stomatal conductance and abscisic acid concentration in spring wheat subjected to artificial drought stress. Ann. Bot. 44:323-332.

Quarrie, S.A. 1980. Genotypic differences in leaf water potential, abscisic acid and proline concentrations in spring wheat during drought stress. Ann. Bot. 46:383-394.

Quarrie, S.A. 1981. Genetic variability and heritability of drought-induced abscisic acid accumulation in spring wheat. Plant Cell Environ. 4:147-151.

Quarrie, S.A. 1989. Abscisic acid as a factor in modifying drought resistance. Environmental stress in plants: Biochemical and physiological mechanism. Springer-Verlag, Berlin, Germany. p. 27-37.

Raschke, K. and R. Hedrich. 1985. Simultaneous and independent effects of abscisic acid on stomata and the photosynthetic apparatus in whole leaves. Planta 163:105-118.

Ridolfi, M. M.L. Fauveau, P. Label, J.P. Garrec, ,and E. Dreyer. 1996. Responses to water stress in an ABA-unresponsive hybrid poplar (Populus koreana $\times$ trichocarpa $\mathrm{cv}$. Peace). I. Stomatal function. New Phytol. 134:445-454.
Samet, J.S., T.R. Sinclair, and P.M. Cortes. 1980. ABA in leaves of field-grown soybean under water stress, p. 366-389. In: D.W. Rains, R.C. Valentine, and A. Hollaender (ed.). Genetic engineering of osmoregulation. Impact on plant productivity for food, chemicals and energy. Plenum, New York.

Sharp, R.E., Y. Wu, G.S. Voetberg, I.N. Saab, and M.E. LeNoble. 1994. Comfirmation that abscisic acid accumulation is required for maize primary root elongation at low water potentials. J. Expt. Bot. 45: $1743-1751$.

Stikic, R. and W.J. Davies. 2000. Stomatal reactions of two different maize lines to osmotically induced drought stress. Biol. Plant. 43: 399-405.

Stoll, M., B. Loveys, and P. Dry. 2000. Hormonal changes induced by partial rootzone drying of irrigated grapevine. J. Expt. Bot. 51: $1627-1634$.

Tamminen, I., P. Makela, P. Heino, and E.T. Palva. 2001. Ectopic expression of $\mathrm{ABI} 3$ gene enhances freezing tolerance in response to abscisic acid and low temperature in Arabidopsis thaliana. Plant J. Cell Mol. Biol. 25:1-8.

Trejo, C.L., A.L. Clephan, and W.J. Davies. 1995. How do stomata read abscisic acid signals? Plant Physiol. 109:803-811.

Wang, Z., B. Huang, and Q. Xu. 2002. Effects of exogenous abscisic acid on drought resistance in two Kentucky bluegrass cultivars. J. Amer. Soc. Hort. Sci. (in press)

Wilkinson, S. and W.J. Davies. 1997. Xylem sap pH increase: a drought signal received at the apoplastic face of the guard cell that involves the suppression of saturable abscisic acid uptake by the epidermal symplast. Plant Physiol. 113:559-573.

Zhang, B. and D.D. Archbold. 1993a. Solute accumulation in leaves of a Fragaria chiloensis and a $F$. virginiana selection responds to water deficit stress. J. Amer. Hort. Sci. 118:280-285.

Zhang, B. and D.D. Archbold. 1993b. Water relations of a Fragaria chiloensis and a $F$. virginiana selection during and after water deficit stress. J. Amer. Soc. Hort. Sci. 118:274-279. 